\title{
Effect of Preoperative Bacteriuria and Pyuria on Intravesical Recurrence in Patients with Upper Tract Urothelial Carcinoma Undergoing Radical Nephroureterectomy
}

\author{
HIROSHI FUKUSHIMA, MASAKI KOBAYASHI, KEIZO KAWANO and SHINJI MORIMOTO \\ Department of Urology, Tsuchiura Kyodo General Hospital, Tsuchiura, Japan
}

\begin{abstract}
Background/Aim: We investigated the effect of bacteriuria and pyuria on intravesical recurrence (IVR) in patients with upper tract urothelial carcinoma (UTUC) undergoing radical nephroureterectomy (RNU). Patients and Methods: Preoperative bacteriuria and pyuria were defined as urine containing $\geq 5$ bacteria/high-power field $(H P F)$ and $>5$ white blood cells/HPF, respectively. Their associations with IVR were evaluated in 97 patients with UTUC undergoing RNU. Results: Preoperative bacteriuria [n=15 (15\%)] was significantly associated with preoperative pyuria [ $n=42$ (43\%), $p<0.001]$. During follow-up (median of 19 months), 45 (46\%) patients developed IVR (median IVR-free survival=38 months). On multivariate analysis, preoperative bacteriuria was an independent predictor for reduced risk of IVR (hazard ratio=0.23, $p=0.010)$. The 2-year IVR-free survival of patients with preoperative bacteriuria and pyuria was significantly longer than that of patients without preoperative bacteriuria ( $83 \%$ vs. 54\%, $p=0.028$ ) and pyuria (69\% vs. $50 \%, p=0.024)$, respectively. Conclusion: Bacteriuria and pyuria may reduce the risk of IVR in patients with UTUC undergoing RNU.
\end{abstract}

Although upper urinary tract carcinoma (UTUC) is a relatively rare disease, its incidence has been increasing and stands at up to two cases per 100,000 person-years in the United States (1). The gold standard of treatment for patients with UTUC is radical nephroureterectomy (RNU).

This article is freely accessible online.

Correspondence to: Hiroshi Fukushima, MD, Department of Urology, Tsuchiura Kyodo General Hospital, 4-1-1 Ootsuno, Tsuchiura, Ibaraki 300-0028, Japan. Tel: +81 298303711, Fax: +81 298463721,e-mail: fukuuro@tmd.ac.jp

Key Words: Bacteriuria, pyuria, upper tract urothelial carcinoma, radical nephroureterectomy, intravesical recurrence.
Intravesical recurrence (IVR) after RNU is a major concern for patients; its reported incidence ranges from 31 to $42 \%$ (2-4). Because of the high frequency of IVR after RNU, patients with UTUC should be followed-up intensively by cystoscopy, an expensive and invasive procedure that results in patient discomfort. To accurately stratify the risk for IVR after RNU, previous studies have reported several prognostic factors, including a history of bladder cancer, ureteral tumor location, higher grade, lower pT stage, and laparoscopic surgical procedure (4-6). However, there is an unmet need to identify novel predictive factors for IVR after RNU, that would aid in appropriate patient counseling and would be helpful in selecting low-risk patients who can avoid close cystoscopic surveillance.

Recently, many researchers have investigated the association between inflammation and cancer (7-9). Some inflammatory and immune responses have antitumor activity, whereas inflammation itself can facilitate cancer progression. Some studies showed that pyuria, which represents local inflammation in the urinary tract, was significantly associated with higher rates of recurrence and progression in patients with non-muscle-invasive bladder cancer (NMIBC) $(10,11)$. Meanwhile, Herr et al. revealed that bacteriuria, which can induce local inflammation in the urinary tract, reduced the risk of recurrence in patients with NMIBC (12). Given that UTUC is clinically and histologically similar to bladder cancer, we hypothesized that preoperative bacteriuria and pyuria may have a possible effect on IVR in patients with UTUC undergoing RNU. The present study aimed to evaluate associations of preoperative bacteriuria and pyuria with IVR in patients with UTUC treated with RNU.

\section{Patients and Methods}

The present study protocol was approved by the Institutional Ethical Committee (Approval number: 580). We retrospectively reviewed 107 consecutive Japanese patients with UTUC undergoing RNU (extrafascial resection of the kidney, entire length of the ureter, and adjacent segment of the bladder cuff) at our Institution between December 2002 and June 2016. After excluding four patients who 
had undergone previous or concurrent radical cystectomy and six with missing data on urine analysis, 97 patients were included for analysis. No patients received neoadjuvant therapy. The dissection of regional lymph nodes was conducted in patients with swollen nodes detected radiologically or intraoperatively. Adjuvant chemotherapy was given at the discretion of physicians. No patients received prophylactic intravesical instillation therapy after RNU. In order to evaluate IVR after RNU, all patients were generally followed-up by cystoscopy and urine cytology every 3 months for the first 2 years, then every 6 months until 5 years, and annually thereafter. IVR was histologically confirmed by transurethral resection of the bladder tumor in each patient who was suspected to have bladder cancer.

The analyzed variables were age at RNU, gender, laterality, Eastern Cooperative Oncology Group performance status (ECOG PS), previous or concomitant bladder cancer, tumor location, tumor focality, tumor grade, $\mathrm{pT}$ and $\mathrm{pN}$ stages, lymphovascular invasion, concomitant carcinoma in situ, adjuvant chemotherapy, and preoperative C-reactive protein (CRP) level. The cut-off value for CRP was based on a previous study (13). Tumor stage and grade were determined according to the 2002 TNM classification (14) and 1973 World Health Organization grading system (15), respectively. LVI was defined as the existence of tumor cells within an endothelium-lined space with no underlying muscular walls.

Urine analysis was conducted at initial presentation and before any transurethral procedures including cystoscopy, insertion of a catheter into the ureter, and ureterorenoscopy. No patients had symptoms suggestive of urinary tract infections (i.e. a burning sensation when urinating). Mid-stream voided urine specimens were collected to prevent bacterial contamination. Preoperative bacteriuria was defined as $\geq 5$ bacteria/high-power field (HPF) in centrifuged urine sediment (16). Preoperative pyuria was defined as $>5$ white blood cells/HPF in centrifuged urine sediment (17).

The distribution of variables between groups was compared using the chi-square test for categorical variables and Wilcoxon rank-sum test for continuous variables. The primary outcome was IVR, and IVR-free survival (IVRFS) was defined as the time from RNU to the first diagnosis of IVR. IVRFS curves were depicted by KaplanMeier method and compared by the log-rank test. Associations of variables with IVRFS were assessed using the Cox proportional hazards model. All statistical analyses were performed using JMP 9.0.2 (SAS Institute Inc., Cary, NC, USA). Two-tailed value of $p<0.05$ was defined as statistically significant.

\section{Results}

Table I summarizes demographics and patient characteristics of the 97 patients. The median (range) age was 75 (49-89) years, and $30(31 \%)$ patients were female. Nine $(9 \%)$ patients had had previous or concomitant bladder cancer. Bacteriuria and pyuria were preoperatively observed in $15(15 \%)$ and $42(43 \%)$ patients, respectively. The relationship between preoperative bacteriuria and other clinicopathological variables is shown in Table I. Preoperative bacteriuria was significantly associated with poorer ECOG PS $(p<0.001)$, higher preoperative CRP $(p<0.001)$, and preoperative pyuria $(p<0.001)$. In addition, preoperative pyuria was significantly associated with higher age $(p=0.025)$ and poorer ECOG PS $(p<0.001)$.
Of the 97 patients, 45 (46\%) developed IVR during a median follow-up of 19 months (range=1-173 months). The median IVRFS was 38 months. On univariate analysis, variables significantly associated with IVR were: tumor grade 3, concomitant carcinoma in situ, lack of preoperative bacteriuria, and lack of preoperative pyuria (Table II). A multivariate analysis revealed that preoperative bacteriuria was an independent predictor for reduced risk of IVR (hazard ratio $=0.23, p=0.010$ ), while tumor grade 3 was a negative prognostic factor (hazard ratio $=1.89, p=0.037$ ). Patients with preoperative bacteriuria had a significantly longer IVRFS than those without (2-year IVRFS: $83 \%$ vs. $54 \%, p=0.028$, Figure 1A). Similarly, a significantly longer IVRFS was observed in patients with preoperative pyuria than those without (2-year IVRFS: $69 \%$ vs. 50\%, $p=0.024$, Figure 1B).

Preoperative bacteriuria and pyuria may be affected by the presence of bladder cancer and its treatment. Thus, we carried out further analysis in 88 patients without previous or concomitant bladder cancer. A similar trend was seen when IVRFS curves were compared according to the presence of preoperative bacteriuria (2-year IVRFS: $83 \% \mathrm{vs}$. $56 \%, p=0.041$ ) and preoperative pyuria (2-year IVRFS: $71 \%$ vs. $53 \%, p=0.023)$.

\section{Discussion}

In the present study, preoperative bacteriuria and pyuria were significantly associated with a longer IVRFS in patients undergoing RNU for UTUC. We obtained very similar results when we analyzed only patients without previous or concomitant bladder cancer, showing these findings were not affected by the presence of bladder cancer and its treatment. Interestingly, preoperative bacteriuria, but not preoperative pyuria, was an independent predictor for reduced risk of IVR after RNU on multivariate analysis. One possible explanation for this phenomenon is that the prognostic significance of preoperative pyuria may be attenuated by preoperative bacteriuria on multivariate analysis, since preoperative bacteriuria was significantly associated with preoperative pyuria. Our findings indicate that bacteriuria and pyuria may have a protective effect against IVR after RNU. Although further investigation is necessary, bacteria might be used as a priming agent to stimulate the immune system to prevent IVR after RNU.

Previous studies showed that preoperative pyuria was significantly associated with higher rates of recurrence and progression in patients with $\operatorname{NMIBC}(10,11)$, which is inconsistent with our findings. These discordant results may be explained by the different etiology of pyuria. In the NMIBC cohort studies, pyuria was considered to represent cancer-associated local inflammation because urine cultures were negative for bacteria in most patients (10). Cancer- 
Table I. Demographics and patient characteristics.

\begin{tabular}{|c|c|c|c|c|}
\hline \multirow[t]{2}{*}{ Variable } & \multirow[t]{2}{*}{ Total, n (\%) } & \multicolumn{2}{|c|}{ Preoperative bacteriuria, n (\%) } & \multirow[t]{2}{*}{$p$-Value } \\
\hline & & Yes & No & \\
\hline No. of patients & $97(100)$ & $15(15)$ & $82(85)$ & \\
\hline Median age at RNU (range), years & $75(49-89)$ & $80(52-87)$ & $74(49-89)$ & 0.061 \\
\hline \multicolumn{5}{|l|}{ Gender } \\
\hline Male & $67(69)$ & $9(60)$ & $58(71)$ & \multirow[t]{2}{*}{0.41} \\
\hline Female & $30(31)$ & $6(40)$ & $24(29)$ & \\
\hline \multicolumn{5}{|l|}{ Laterality } \\
\hline Right & $42(43)$ & $6(40)$ & $36(44)$ & \multirow[t]{2}{*}{0.78} \\
\hline Left & $55(57)$ & $9(60)$ & $46(56)$ & \\
\hline \multicolumn{5}{|l|}{ ECOG PS } \\
\hline 0 & $81(84)$ & $8(53)$ & $73(89)$ & \multirow[t]{2}{*}{$<0.001$} \\
\hline$\geq 1$ & $16(16)$ & $7(47)$ & $9(11)$ & \\
\hline \multicolumn{5}{|c|}{ Previous or concomitant bladder cancer } \\
\hline No & $88(91)$ & $15(100)$ & $73(89)$ & \multirow[t]{2}{*}{0.18} \\
\hline Yes & $9(9)$ & $0(0)$ & $9(11)$ & \\
\hline \multicolumn{5}{|l|}{ Tumor location } \\
\hline Kidney & $38(39)$ & $4(27)$ & $34(41)$ & \multirow[t]{3}{*}{0.11} \\
\hline Ureter & $44(45)$ & $6(40)$ & $38(46)$ & \\
\hline Both & $15(16)$ & $5(33)$ & $10(12)$ & \\
\hline \multicolumn{5}{|l|}{ Tumor focality } \\
\hline Solitary & $75(77)$ & $11(73)$ & $64(78)$ & \multirow[t]{2}{*}{0.69} \\
\hline Multiple & $22(23)$ & $4(27)$ & $18(22)$ & \\
\hline \multicolumn{5}{|l|}{ Tumor grade } \\
\hline $1 / 2$ & $48(49)$ & $7(47)$ & $41(50)$ & \multirow[t]{2}{*}{0.81} \\
\hline 3 & $49(51)$ & $8(53)$ & $41(50)$ & \\
\hline \multicolumn{5}{|l|}{ pT stage } \\
\hline pTa-2 & $66(68)$ & $7(47)$ & $59(72)$ & \multirow[t]{2}{*}{0.054} \\
\hline pT3/4 & $31(32)$ & $8(53)$ & $23(28)$ & \\
\hline \multicolumn{5}{|l|}{ pN stage } \\
\hline pNO & $9(9)$ & $3(20)$ & $6(7)$ & \multirow[t]{3}{*}{0.26} \\
\hline $\mathrm{pNx}$ & $86(89)$ & $12(80)$ & $74(90)$ & \\
\hline $\mathrm{pN}+$ & $2(2)$ & $0(0)$ & $2(2)$ & \\
\hline \multicolumn{5}{|l|}{ LVI } \\
\hline No & $61(63)$ & $7(47)$ & $54(66)$ & 0.16 \\
\hline Yes & $36(37)$ & $8(53)$ & $28(34)$ & \\
\hline Concomitant carcinoma in situ & & & & \\
\hline No & $63(65)$ & $13(87)$ & $50(61)$ & 0.056 \\
\hline Yes & $34(35)$ & $2(13)$ & $32(39)$ & \\
\hline Adjuvant chemotherapy & & & & \\
\hline No & $70(72)$ & $11(73)$ & $59(72)$ & 0.91 \\
\hline Yes & $27(28)$ & $4(27)$ & $23(28)$ & \\
\hline Preoperative CRP & & & & \\
\hline$<5 \mathrm{mg} / \mathrm{l}$ & $74(76)$ & $6(40)$ & $68(83)$ & $<0.001$ \\
\hline$\geq 5 \mathrm{mg} / 1$ & $23(24)$ & $9(60)$ & $14(17)$ & \\
\hline Preoperative pyuria & & & & \\
\hline No & $55(57)$ & $2(13)$ & $53(65)$ & $<0.001$ \\
\hline Yes & $42(43)$ & $13(87)$ & $29(35)$ & \\
\hline
\end{tabular}

CRP: C-Reactive protein; ECOG PS: Eastern Cooperative Oncology Group performance status; LVI: lymphovascular invasion; RNU: radical nephroureterectomy.

associated inflammation can promote the proliferation and invasion of cancer cells within the tumor microenviroment (18). Leukocytes are reported as important players in cancer-associated inflammation (19). Pyuria might have been caused by the presence of bacteriuria in our UTUC cohort, given that preoperative bacteriuria was significantly associated with the presence of preoperative pyuria in the present study. Bacteria in the bladder could induce immune 
Table II. Univariate and multivariate analyses for predicting intravesical recurrence-free survival

\begin{tabular}{|c|c|c|c|c|}
\hline \multirow[b]{2}{*}{ Variable } & \multirow{2}{*}{$\begin{array}{c}\text { Univariate } \\
p \text {-Value }\end{array}$} & \multicolumn{3}{|c|}{ Multivariate } \\
\hline & & HR & $95 \% \mathrm{CI}$ & $p$-Value \\
\hline Age at RNU (years) & & 0.77 & & \\
\hline Gender & & & & \\
\hline $\begin{array}{l}\text { Male } \\
\text { Female }\end{array}$ & 0.55 & & & \\
\hline Laterality & & & & \\
\hline $\begin{array}{l}\text { Right } \\
\text { Left }\end{array}$ & 0.51 & & & \\
\hline ECOG PS & & & & \\
\hline $\begin{array}{l}0 \\
1 \leq\end{array}$ & 0.60 & & & \\
\hline $\begin{array}{l}\text { Previous or concomitant } \\
\text { bladder cancer }\end{array}$ & & & & \\
\hline $\begin{array}{l}\text { No } \\
\text { Yes }\end{array}$ & 0.062 & & & \\
\hline Tumor location & & & & \\
\hline $\begin{array}{l}\text { Kidney } \\
\text { Ureter/both }\end{array}$ & 0.16 & & & \\
\hline Tumor focality & & & & \\
\hline $\begin{array}{l}\text { Solitary } \\
\text { Multiple }\end{array}$ & 0.52 & & & \\
\hline Tumor grade & & & & \\
\hline $\begin{array}{l}1 / 2 \\
3\end{array}$ & 0.042 & $\begin{array}{l}\text { Ref. } \\
1.89\end{array}$ & $1.04-3.49$ & 0.037 \\
\hline pT stage & & & & \\
\hline $\begin{array}{l}\text { pTa-2 } \\
\text { pT3/4 }\end{array}$ & 0.11 & & & \\
\hline pN stage & & & & \\
\hline $\begin{array}{l}\mathrm{pN} 0 / \mathrm{x} \\
\mathrm{pN}+\end{array}$ & 0.74 & & & \\
\hline $\begin{array}{l}\text { LVI } \\
\text { Yes }\end{array}$ & No & 0.28 & & \\
\hline Concomitant carcinoma $i$ & situ & & & \\
\hline $\begin{array}{l}\text { No } \\
\text { Yes }\end{array}$ & 0.046 & & & \\
\hline $\begin{array}{l}\text { Adjuvant chemotherapy } \\
\text { Yes }\end{array}$ & No & 0.56 & & \\
\hline $\begin{array}{l}\text { Preoperative CRP } \\
\quad<5 \mathrm{mg} / 1 \\
\geq 5 \mathrm{mg} / 1\end{array}$ & 0.65 & & & \\
\hline Preoperative bacteriuria & & & & \\
\hline $\begin{array}{l}\text { No } \\
\text { Yes }\end{array}$ & 0.011 & $\begin{array}{l}\text { Ref. } \\
0.23\end{array}$ & $0.04-0.74$ & 0.010 \\
\hline $\begin{array}{l}\text { Preoperative pyuria } \\
\text { No } \\
\text { Yes }\end{array}$ & 0.021 & & & \\
\hline
\end{tabular}

CI: Confidence interval; CRP: C-reactive protein; ECOG PS: Eastern Cooperative Oncology Group performance status; HR: hazard ratio; LVI: lymphovascular invasion; RNU: radical nephroureterectomy; Ref: reference.

responses protecting from urinary tract infections and possibly cancer (20). Recently, Herr et al. found that preoperative bacteriuria reduced the risk of recurrence in patients with NMIBC (12). Therefore, a bacteria-associated immune response may suppress the initiation and development of bladder cancer, a response which might potentially be similar to an immune response caused by the intravesical instillation of bacillus Calmette-Guerin.

A single retrospective study showed that preoperative pyuria was a significant predictor for higher $\mathrm{pT}$ stage and worse overall survival (OS) in patients with UTUC treated with RNU (21). In the present study, patients with preoperative pyuria had worse OS than those without (5-year OS: $85 \%$ vs. $76 \%, p=0.044$, data not shown), corresponding with the finding of the previous study. Interestingly, preoperative pyuria was significantly associated with poorer ECOG PS and higher age in the present study. Therefore, preoperative pyuria may reflect patient frailty. Reportedly, sarcopenia, a strong indicator of patient frailty, was significantly associated with higher pT stage and worse OS in patients treated with RNU for UTUC $(22,23)$.

The present study has several limitations. Firstly, it was a retrospective analysis of a relatively small patient population. Thus, our findings need to be validated in a prospective larger multicenter study. Secondly, the results of urine culture, which might reveal which bacterial species could elicit an antitumor effect in the bladder, were not available in the present study. Although the definition of bacteriuria used in the present study was not based on the results of urine culture, a value of 5 bacteria/HPF represents roughly 100,000 colony-forming units/ml in urine culture (16), which is the classic diagnostic criterion for bacteriuria. Moreover, our definition is easy to use in clinical practice because microscopic analysis of urine sediment is a quick and inexpensive screening method. Thirdly, urine specimens from female patients can be contaminated by vaginal flora, even though urine specimens were collected in the midstream of urination. However, preoperative bacteriuria remained significantly associated with lower rates of IVR when analyzed only among male patients in our cohort (data not shown).

In conclusion, we demonstrated that preoperative bacteriuria and pyuria were significantly associated with a longer IVRFS after RNU. Although our preliminary findings should be validated in a larger multicenter patient cohort, they raise the possibility that bacteriuria and pyuria may have a protective effect against IVR after RNU. Future studies might clarify the role of bacterial priming, which may stimulate the immune system to prevent IVR in patients undergoing RNU for UTUC.

\section{References}

1 Raman JD, Messer J, Sielatycki JA and Hollenbeak CS: Incidence and survival of patients with carcinoma of the ureter and renal pelvis in the USA, 1973-2005. BJU Int 107: 1059-1064, 2011. 
A

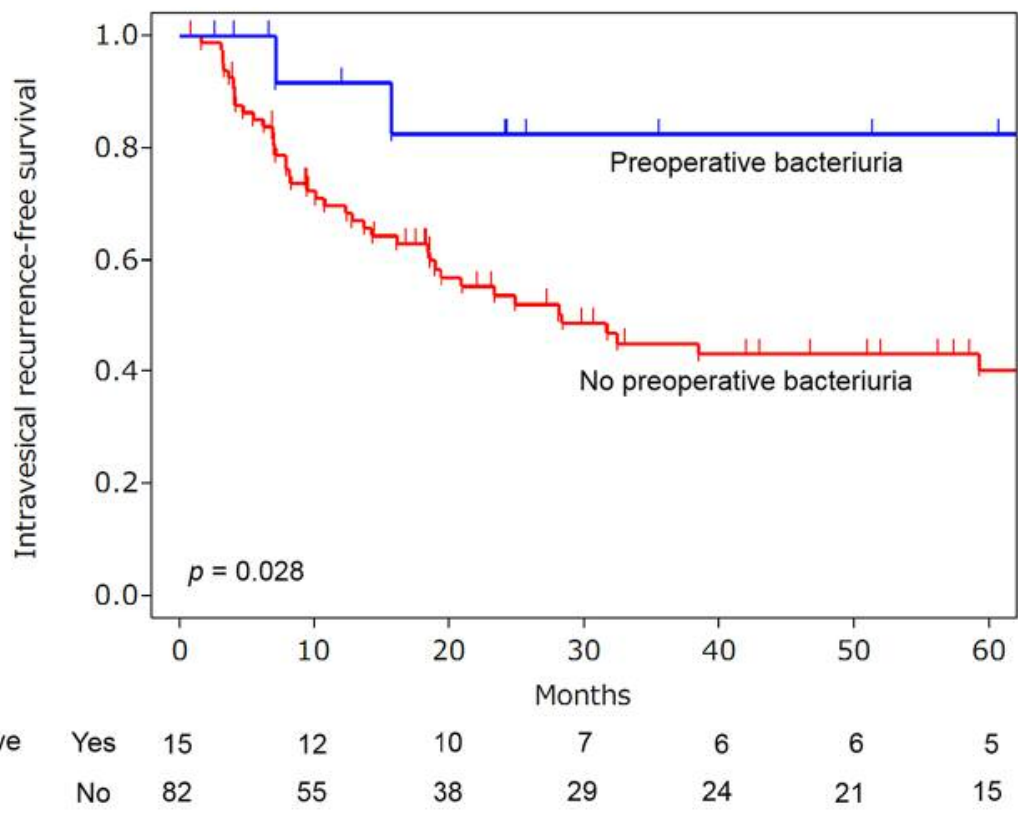

No. at risk

\begin{tabular}{|c|c|c|c|c|c|c|c|}
\hline \multirow{2}{*}{$\begin{array}{l}\text { Preoperative } \\
\text { bacteriuria }\end{array}$} & Yes & 15 & 12 & 10 & 7 & 6 & 6 \\
\hline & No & 82 & 55 & 38 & 29 & 24 & 21 \\
\hline
\end{tabular}

B

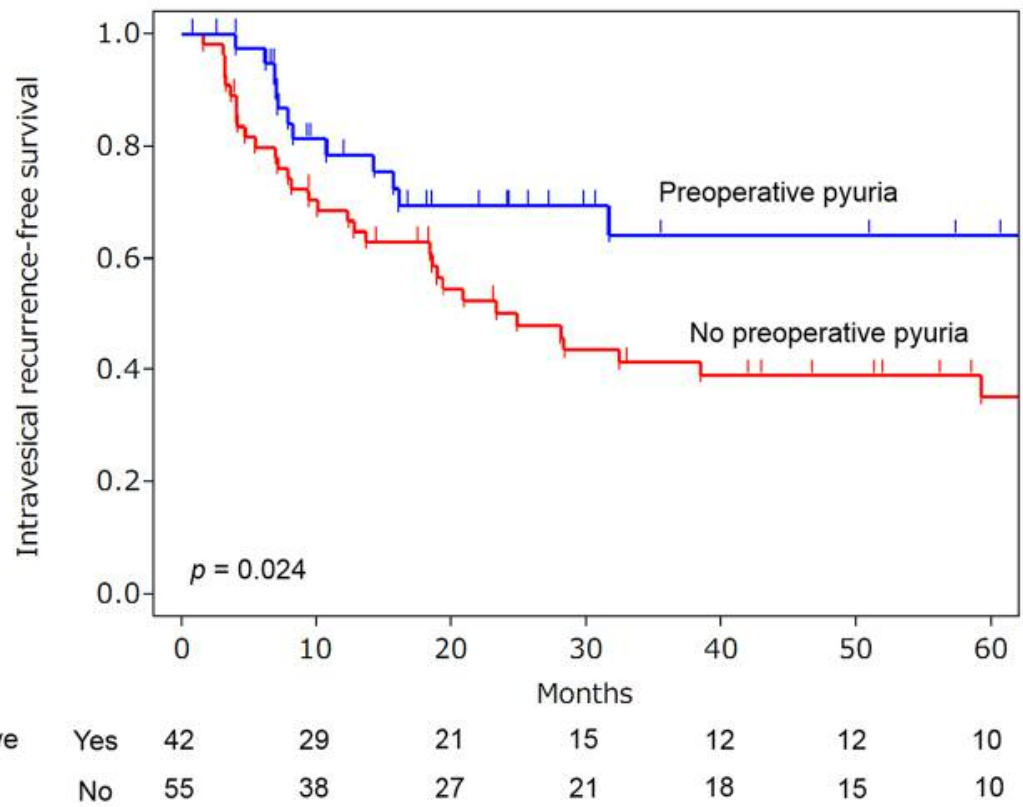

Figure 1. Intravesical recurrence-free survival curves according to the presence of preoperative bacteriuria (A) and preoperative pyuria (B).

2 Xylinas E, Colin P, Audenet F, Phe V, Cormier L, Cussenot O, Houlgatte A, Karsenty G, Bruyere F, Polguer T, Ruffion A, Valeri A, Rozet F, Long JA, Zerbib $\mathrm{M}$ and Roupret $\mathrm{M}$ : Intravesical recurrence after radical nephroureterectomy for upper tract urothelial carcinomas: predictors and impact on subsequent oncological outcomes from a national multicenter study. World J Urol 31: 61-68, 2013.

3 Matsui Y, Utsunomiya N, Ichioka K, Ueda N, Yoshimura K, Terai A and Arai Y: Risk factors for subsequent development of bladder cancer after primary transitional cell carcinoma of the upper urinary tract. Urology 65: 279-283, 2005.

4 Xylinas E, Kluth L, Passoni N, Trinh QD, Rieken M, Lee RK, Fajkovic H, Novara G, Margulis V, Raman JD, Lotan Y, Roupret M, Aziz A, Fritsche HM, Weizer A, Martinez-Salamanca JI, Matsumoto K, Seitz C, Remzi M, Walton T, Karakiewicz PI, Montorsi F, Zerbib M, Scherr DS and Shariat SF: Prediction of intravesical recurrence after radical nephroureterectomy: development of a clinical decisionmaking tool. Eur Urol 65: 650-658, 2014. 
5 Yuan H, Chen X, Liu L, Yang L, Pu C, Li J, Bai Y, Han P and Wei Q: Risk factors for intravesical recurrence after radical nephroureterectomy for upper tract urothelial carcinoma: a metaanalysis. Urol Oncol 32: 989-1002, 2014.

6 Terakawa T, Miyake H, Muramaki M, Takenaka A, Hara I and Fujisawa M: Risk factors for intravesical recurrence after surgical management of transitional cell carcinoma of the upper urinary tract. Urology 71: 123-127, 2008.

7 Gakis G: The role of inflammation in bladder cancer. Adv Exp Med Biol 816: 183-196, 2014.

8 Redelman-Sidi G, Glickman MS and Bochner BH: The mechanism of action of BCG therapy for bladder cancer-a current perspective. Nat Rev Urol 11: 153-162, 2014.

9 Coussens LM and Werb Z: Inflammation and cancer. Nature 420: 860-867, 2002.

10 Azuma T, Nagase Y and Oshi M: Pyuria predicts poor prognosis in patients with non-muscle-invasive bladder cancer. Clin Genitourin Cancer 11: 331-336, 2013.

11 Satake N, Ohno Y, Nakashima J, Ohori M and Tachibana M: Prognostic value of preoperative pyuria in patients with nonmuscle-invasive bladder cancer. Int J Urol 22: 645-649, 2015.

12 Herr $\mathrm{H}$ and Donat SM: Commentary: Does asymptomatic bacteriuria reduce the risk of recurrence of non-muscle-invasive bladder tumors? Urology 98: 1-3, 2016.

13 Saito K, Kawakami S, Ohtsuka Y, Fujii Y, Masuda H, Kumagai J, Kobayashi T, Kageyama Y and Kihara K: The impact of preoperative serum $\mathrm{C}$-reactive protein on the prognosis of patients with upper urinary tract urothelial carcinoma treated surgically. BJU Int 100: 269-273, 2007.

14 Sobin LH and Wittekind C: TNM Classification of Malignant Tumors, 6th Edition New York, Wiley, 2002.

15 Mostofi FK, Sobin LH and Torloni H: International Histological Classification of Tumors: Histological Typing of Urinary Bladder Tumors. World Health Organization, Geneva, 1973.
16 Simerville JA, Maxted WC and Pahira JJ: Urinalysis: a comprehensive review. Am Fam Physician 71: 1153-1162, 2005.

17 Hooker JB, Mold JW and Kumar S: Sterile pyuria in patients admitted to the hospital with infections outside of the urinary tract. J Am Board Fam Med 27: 97-103, 2014.

18 Whiteside TL: The tumor microenvironment and its role in promoting tumor growth. Oncogene 27: 5904-5912, 2008.

19 Jablonska J, Leschner S, Westphal K, Lienenklaus S and Weiss $\mathrm{S}$ : Neutrophils responsive to endogenous IFN-beta regulate tumor angiogenesis and growth in a mouse tumor model. J Clin Invest 120: 1151-1164, 2010 .

20 Ingersoll MA and Albert ML: From infection to immunotherapy: host immune responses to bacteria at the bladder mucosa. Mucosal Immunol 6: 1041-1053, 2013.

21 Liang C, Wang J, Liu H, Huang L, Xu D, Qian S, Qian X and Qi J: Preoperative pyuria predicts advanced pathologic tumor stage and worse survival in patients with urothelial carcinoma of the upper urinary tract treated by radical nephroureterectomy. Urol Oncol 34: 418.e411-417, 2016.

22 Fukushima $\mathrm{H}$ and Koga F: Impact of sarcopenia in the management of urological cancer patients. Expert Rev Anticancer Ther 17: 455-466, 2017.

23 Fukushima H, Nakanishi Y, Kataoka M, Tobisu K and Koga F: Prognostic significance of sarcopenia in upper tract urothelial carcinoma patients treated with radical nephroureterectomy. Cancer Med 5: 2213-2220, 2016.
Received July 28, 2017

Revised August 11, 2017

Accepted August 21, 2017 